\title{
PROGRAMA ARBORETUM COMO POTENCIALIZADOR DA AGENDA 2030 NA MATA ATLÂNTICA DO EXTREMO SUL DA BAHIA
}

\author{
AUTOR: DANILO FERREIRA ALMEIDA FARIAS \\ CO-AUTOR: FREDERICO MONTEIRO NEVES \\ CO-AUTOR/ORIENTADOR: GUINEVERRE ALVAREZ MACHADO DE MELO GOMES
}

\begin{abstract}
Resumo: A ciência da atribuição climática nos tem apresentado evidências científicas contemporâneas incontestáveis de que as mudanças climáticas impulsionadas pela ação humana têm potencializado inúmeras calamidades globais. A esse contexto é preocupante a realidade de grupos vulneráveis que mais sofrem e sofrerão com a crise climática. Esse quadro climático e outras preocupações internacionais mobilizaram esforços da comunidade internacional em anseios para conter a instabilidade climática através de medidas de adaptação e mitigação. Todo esse panorama associado a cooperação internacional preocupada como os problemas relacionados ao meio ambiente e aos Direitos Humanos resultou na criação da Agenda 2030 para o Desenvolvimento Sustentável, que estabelece 17 Objetivos do Desenvolvimento Sustentável (ODS), com pretensões variadas em especial o da redução de desigualdades (ODS 10) e a ação contra a mudança global do Clima (ODS 13). Alguns desafios para a efetiva implementação da Agenda 2030 é que será necessária a observação da realidade de cada país signatário e o empenho dos entes políticos e dos diversos atores sociais, em especial daqueles no plano local. Neste sentido, este projeto de pesquisa analisou as contribuições de uma iniciativa local, o Programa Arboretum de Conservação e Restauração da Diversidade Florestal, para as metas dos ODS na região da mata atlântica do extremo sul da Bahia. Para tanto, realizou-se coleta, tratamento e análise de dados variados, como análises bibliográfica e documental, grupos focais, entrevistas semiestruturas e questionários semiestruturados. Os resultados sinalizam que as ações do Programa Arboretum contribuem para alcance e efetivação da Agenda 2030 uma vez que suas atividades se relacionam e estão alinhadas com vários Objetivos do Desenvolvimento Sustentável, traduzindo não só a realidade brasileira como atuando de maneira municipal e regional em atividades de manejo florestal.
\end{abstract}

Palavras-chave: Agenda 2030, ODS, Programa Arboretum. 